\title{
Production of histamine and tyramine by bacteria isolated from Portuguese vacuum-packed cold-smoked fish
}

\author{
Manuela V. da Silva ${ }^{\mathrm{a}, *}$, Olívia Pinho ${ }^{\mathrm{b}}$, Isabel Ferreira ${ }^{\mathrm{b}}$, Linda Plestilová ${ }^{\mathrm{c}}$, \\ Paul A. Gibbs ${ }^{\text {a,d }}$

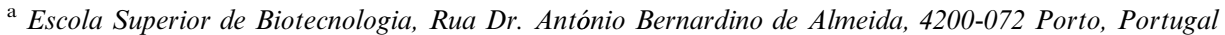 \\ ${ }^{\mathrm{b}}$ CEQUP/Serviço de Bromatologia, Faculdade de Farmácia da Universidade do Porto, R. Aníbal Cunha 164, 4050 Porto, Portugal \\ ${ }^{c}$ Institut of Chemical Technology, Prague University, Czech Republic \\ d Leatherhead Food Research Association, Surrey, UK
}

Keywords: Histamine; Tyramine; Biogenic amines; Decarboxylating bacteria; Cold-smoked fish

\begin{abstract}
An agar medium containing histidine or tyrosine incubated anaerobically was used for detecting the decarboxylating activity of bacteria isolated from Portuguese vacuum-packed cold-smoked fish during chilled storage. The capacity of each bacterial isolate to produce histamine and tyramine was studied at 25 and $5{ }^{\circ} \mathrm{C}$ incubated for $48 \mathrm{~h}$ and 10 days, respectively. More strains produced histamine and tyramine at $25^{\circ} \mathrm{C}$ compared with $5{ }^{\circ} \mathrm{C}$ although lactic acid bacteria (LAB) strains exhibited similar results at the two different temperatures. Tyramine was produced by majority of the isolates tested although very low concentrations were produced at $5{ }^{\circ} \mathrm{C}$ as confirmed by high-pressure liquid chromatography (HPLC). Tyrosine-agar was shown to be a good indicator medium for detection of bacteria that produced high levels of tyramine, since typical colonies surrounded by a translucent halo were easily recognised. LAB identified as Lc. Lactis lactis 1 and Carnobacterium divergens were detected as tyramine-producing bacteria. Acinetobacter spp. and Pseudomonas spp., isolated from all Portuguese smoked fish products, were negative on histidine-agar, but HPLC identified considerable quantities of histamine produced in a broth medium.
\end{abstract}

(C) 2002 Elsevier Science Ltd. All rights reserved.

\section{Introduction}

Many authors have discussed the toxicology of biogenic amines and their occurrence and formation in foods, with special emphasis on fermented foods. Several biogenic amines play important roles in many human and animal physiological functions (ten Brink, Damink, Joosten, \& Huis in't Veld, 1990) but the consumption of high amounts of these amines can have toxicological effects. The most notorious food-borne intoxications caused by biogenic amines are related to histamine, referred to as "scombroid fish poisoning". On the other hand, the toxicology of tyramine is usually associated with cheese consumption.

Furthermore, biogenic amines have been used as chemical indicators of seafood quality especially on vac-

\footnotetext{
*Corresponding author. Fax: +351-2-509-0351.

E-mail address: mvsilva@morango.esb.ucp.pt (M.V. da Silva).
}

uum-packed cold-smoked salmon (Jorgensen, Huss, \& Dalgaard, 2000a). The same authors showed four different biogenic amine profiles at the time of spoilage in cold-smoked salmon, and these were dependent on the composition of the spoilage microflora. Research on identification of spoilage microflora and biogenic amine production of single and co-cultures growing in coldsmoked salmon was also studied by Jorgensen, Dalgaard, and Huss (2000b). Strains of Enterobacteriaceae and lactic acid bacteria (LAB) are the main microflora associated with cold-smoked fish and identified as active amine producers (Joosten \& Northolt, 1989; Jorgensen et al., 2000a; Leisner, Millan, Huss, \& Larsen, 1994).

Truelstrup Hansen (1995) described three scenarios that characterise the spoilage microflora in cold-smoked salmon: (i) LAB, (ii) dominance of a mixture of LAB and Enterobacteriaceae and (iii) dominance by Photobacterium phosphoreum or other marine members of the Vibrionaceae family, often together with LAB. With respect to biogenic amine production, Jorgensen et al. (2000b) 
showed that $P$. phosphoreum was the only species that produced histamine when inoculated on sterile coldsmoked salmon and the production of putrescine was increased when cultures of Serratia liquefaciens or Hafnia alvei were grown with Carnobacterium divergens or Lactobacillus sakei subs. carnosus.

Biogenic amines in foods are usually generated by microbial decarboxylation of amino acids present in muscle tissues. Several factors (the incubation temperature, the $\mathrm{pH}$ and the growth medium composition) are known to affect bacterial growth and decarboxylase activity. Differential agar media were used in various previous studies on selection or on recognition of decarboxylating bacteria from fish (Chen, Wei, Koburger, \& Marshall, 1989; Leisner et al., 1994; Niven, Jeffrey, \& Corlett, 1981) and other food products (Actis, Smoot, Barancin, \& Findlay, 1999; Joosten \& Northolt, 1989; Maijala, 1993).

Based on high detection rates (93.9\%) obtained using Niven's medium (Niven et al., 1981) to select histamineproducing bacteria (Chen et al., 1989), this medium was selected in this study as a differential agar medium to detect histamine- and tyramine-producing bacteria that have been isolated from Portuguese cold-smoked fish. Also, a modified decarboxylation agar proposed by Maijala (1993) was included in this study for detection of the same amines produced by LAB. Histamine and tyramine are reported as the more important biogenic amines that contribute to spoilage on cold-smoked salmon and are produced especially by $P$. phosphoreum and Carnobacterium piscicola, respectively (Jorgensen et al., 2000a). The purpose of this investigation was to study the production of amines by bacterial strains that formed the dominant microflora on Portuguese vacuumpacked cold-smoked fish stored at $5{ }^{\circ} \mathrm{C}$, using decarboxylation agars and confirmation by high-pressure liquid chromatography (HPLC).

\section{Materials and methods}

\subsection{Cold-smoked fish samples}

Vacuum-packed cold-smoked fish samples stored at $5{ }^{\circ} \mathrm{C}$ were obtained from three different Portuguese smokehouses, during week storage.

\subsection{Microbiological analysis}

Vacuum packs of cold-smoked fish were stored at $5{ }^{\circ} \mathrm{C}$ for up to 5 weeks. At weekly intervals, a pack from each smokehouse was opened and $30 \mathrm{~g}$ of cold-smoked fish was taken aseptically $(10+10+10 \mathrm{~g}$, from different sites) and homogenised for $90 \mathrm{~s}$ in a stomacher. $10 \mathrm{~g}$ of this mixture was aseptically taken and decimally diluted in sterile maximum recovery diluent (CM 733 Oxoid) and homogenised for 20 s. Total viable counts were performed on spread plates of Long and Hammer's medium (LH) modified by Van Spreekens (1974) (with additional $1 \% \mathrm{w} / \mathrm{v} \mathrm{NaCl}$ ) incubated aerobically at $21{ }^{\circ} \mathrm{C}$ for 3 days. Counts of LAB were made on pour plates of nitrite-actidione-polymyxin (NAP) agar $\mathrm{pH} 6.7$ (Davidson \& Cronin, 1973) incubated anaerobically (Anaerocult A, Merck) at $21{ }^{\circ} \mathrm{C}$ for 5 days. Enterobacteriaceae counts were made by pour plates of $5 \mathrm{ml}$ tryptone soya agar (TSA) (Lab M), which after incubation at $20-25^{\circ} \mathrm{C}$ for $2 \mathrm{~h}$ were overlaid by $12-15 \mathrm{ml}$ of violet red bile glucose agar (Merck) (TSA/VRBGA). Typical Enterobacteriaceae colonies were counted after 2 days incubation at $30^{\circ} \mathrm{C}$.

\section{Bacterial isolates}

Representative colonies that grew on Long and Hammer's plates were picked and the following tests were performed: cell morphology, Gram stain, catalase and oxidase tests. The cultures were maintained on nutrient agar slants and stored at $5{ }^{\circ} \mathrm{C}$. Identification of the LAB group was based on the Gram reaction, absence of catalase and cytochrome oxidase and fermentative catabolism of glucose. For selected strains API 20N (BioMérieux) and API 50CHL (BioMérieux) were used for identification of Gram negative strains and $L A B$, respectively.

A strain of $C$. divergens previously isolated from coldsmoked salmon and obtained from the culture collection of ENITIAA (Nantes) was included in this study as a reference.

\section{Examination of amine-forming capacity}

Thirty one Gram-negative and 17 strains that were included in the LAB group were selected to investigate the decarboxylating capacity.

Media used to detect decarboxylating strains was prepared as described by Niven et al. (1981) $(0.5 \%$ tryptone $(\mathrm{Lab} \mathrm{M}), 0.5 \%$ yeast extract $(\mathrm{Lab} \mathrm{M}), 2.0 \%$ L-histidine-monohydrochloride (Oxoid) or L-tyrosine (Oxoid), $0.5 \% \mathrm{NaCl}$ (Merck), $0.1 \% \mathrm{CaCO}_{3}$ (Merck), $2.0 \%$ agar (Lab M) and $0.006 \%$ bromocresol purple, at $\mathrm{pH}$ 5.3). Additionally, the decarboxylation agar proposed by Maijala (1993), a modified version of the medium described by Joosten and Northolt (1989), was also used to detect decarboxylating LAB strains $(0.5 \%$ tryptone (Lab M), 0.8\% Lab-Lemco powder (Oxoid), $0.4 \%$ yeast extract $(\mathrm{Lab} \mathrm{M}), 2.0 \% \mathrm{~L}$-histidine-monohydrochloride (Oxoid) or L-tyrosine (Oxoid), $0.05 \%$ Tween 80 (Merck), $0.02 \% \quad \mathrm{MgSO}_{4}$ (Merck), $0.005 \% \quad \mathrm{MnSO}_{4}$ (Merck), $\quad 0.004 \% \quad \mathrm{FeSO}_{4} \quad$ (Merck), $0.01 \% \mathrm{CaCO}_{3}$ (Merck), 2\% agar (Lab M) and $0.006 \%$ bromocresol 
purple, at $\mathrm{pH}$ 5.3). Both media were autoclaved for 10 min at $121{ }^{\circ} \mathrm{C}$ to avoid excessive hydrolysis of the agar at low $\mathrm{pH}$.

Strains were prepared for testing by subculturing in nutrient broth (NB) (Lab M) supplemented with $0.4 \%$ each of the amino acids histidine or tyrosine and incubated at $25{ }^{\circ} \mathrm{C}$ for $48 \mathrm{~h}$. A loop of each culture was spread on the decarboxylation agars which were then incubated anaerobically (Anaerocult A, Merck) at 25 and $5{ }^{\circ} \mathrm{C}$ for $48 \mathrm{~h}$ and 10 days, respectively. A purple halo was interpreted as positive for amine production on both media with the exception of the decarboxylation media containing tyrosine that also produced a clear halo surrounding the colonies for a positive reaction, as proposed by Joosten and Northolt (1989).

All the strains were tested twice on separate occasions.

\subsection{Analysis of broth culture media for amines}

For selected strains that were on dominance on coldsmoked fish samples, a pre-culture were prepared as described above and $100 \mu 1$ of each pre-culture was inoculated into $5 \mathrm{ml}$ of $\mathrm{NB}$ (Lab M) supplemented with $0.4 \%$ of histidine or tyrosine and incubated at $5{ }^{\circ} \mathrm{C}$ for 25 days.

One $\mathrm{ml}$ of the culture fluid was mixed with $1 \mathrm{ml}$ of hydrochloride acid solution $(0.1 \mathrm{M})$ (Fluka), homogenised and kept in an ultrasonic bath for $15 \mathrm{~min}$ and then filtered through a $0.22 \mu \mathrm{m}$ membrane (Technokroma). The filtrate was centrifuged for $5 \mathrm{~min}$ and $30 \mu \mathrm{l}$ of the filtrate was derivatised using dabsyl chloride at 70 ${ }^{\circ} \mathrm{C}$ for $15 \mathrm{~min}$. The reaction was stopped by placing the vials in an ice bath for $5 \mathrm{~min}$. The dabsylated derivates were diluted in a mixture of acetonitrile and ethanol and after centrifugation, separation and quantification of tyramine and histamine were performed by using HPLC.

The chromatographic analyses were carried out in a JASCO high performance liquid chromatograph equipped with a JASCO PU-1580 pump, a JASCO LG1580-04 quaternary gradient unit, a type 7125 Rheodyne Injector with a $20 \mu \mathrm{l}$ loop, a Gilson model (temperature control module) oven and with a JASCO UV-970 UV/ Vis detector. The integrator used was a Borwin PDA controller software.

The separations were performed at $50{ }^{\circ} \mathrm{C}$ on a $150 \times 4 \mathrm{~mm}^{2}$ I. D. Spherisorb ODS C 18 column, $3 \mu \mathrm{m}$. Dabsylated amines were eluted at a flow-rate of $1 \mathrm{ml} /$ min using a gradient made with mobile phase (A), consisting of $9 \mathrm{mM}$ sodium dihydrogen-ortho-phosphate, $4 \%$ dimethylformamide and $0.1 \%$ triethylamine (TEA), titrated to $\mathrm{pH} 6.55$ with phosphoric acid and mobile phase (B) was $80 \%(\mathrm{v} / \mathrm{v})$ aqueous acetonitrile (Krause, Bockhardt, Neckermann, Henle, \& Kloster- meyer, 1995). Detection was at $436 \mathrm{~nm}$. Quantification was carried out using histamine and tyramine standards.

\section{Results and discussion}

LAB were determined as the dominant group present in Portuguese vacuum-pack cold-smoked fish and is in agreement with other previous studies (Jorgensen et al., 2000b; Leisner et al., 1994; Truelstrup Hansen, 1995). There were some differences in the development of LAB and Enterobacteriaceae in products from the three smokehouses (data not shown).

From the studies using the agar media, strains of decarboxylating bacteria were identified based on the appearance of a purple colour around the colonies (Table 1). Niven's agar identified $26 \%$ and $13 \%$ of histamine-producing Gram-negative bacteria at 25 and 5 ${ }^{\circ} \mathrm{C}$, respectively (Table 1). Most of these bacteria belong to the genera Serratia and Enterobacter (results not shown) and these seem to be the most frequently isolated Enterobacteriaceae from cold-smoked salmon (Jorgensen et al., 2000a; Truelstrup Hansen \& Huss, 1995). Niven's agar was used in previous studies and showed a high detection rate of histamine-producing bacteria (Chen et al., 1989; Joosten \& Northolt, 1989). In the present study, additional confirmation of histamine and tyramine production by HPLC was studied on selected bacterial strains (Table 2). One false positive and two false negative results for histamine detection were observed for bacterial strains tested on agar media. In fact the agar media test is based on the production of an alkaline reaction and not on the specific detection of histamine. The production of ammonia and not histamine can be a reason for false positive detection on agar (Actis et al., 1999; Jorgensen et al., 2000a). In contrast, false negative reactions can occur on differential plating media based on excessive acid production that consequently neutralises the increase of $\mathrm{pH}$ resulting from amine production. Actis et al. (1999) observed that $\mathrm{pH}$ was increased by about two units by histamine-producing bacteria but was drastically reduced when the histidine-containing medium was supplemented with peptone, beef extract and glucose. In the current study, Pseudomonas spp. and Acinetobacter spp. were identified as two strong histamine producers that did not show a positive reaction on Niven's agar. These particular bacteria are not very common on cold-smoked salmon but in fact were isolated from products from all smokehouses. In contrast, bacteria commonly isolated from these type of products such as $P$. phosphoreum (Jorgensen et al., 2000b) showed that only $6 \%$ of these strains produced an alkaline reaction from histidine in Falkow's medium. Also, Hafnia alvei failed to show a positive reaction colour change in Niven's medium (Chen et al., 1989). 
Table 1

Number of positive histamine and tyramine-producing bacteria determined using decarboxylation agars

\begin{tabular}{|c|c|c|c|c|c|c|}
\hline & \multicolumn{4}{|c|}{ Decarboxylation agar (Niven et al., 1981) } & \multirow{2}{*}{\multicolumn{2}{|c|}{$\begin{array}{l}\text { Decarboxylation agar (Maijala, 1993) } \\
\text { At } 5^{\circ} \mathrm{C}, 10 \text { days }\end{array}$}} \\
\hline & \multicolumn{2}{|c|}{ At $25^{\circ} \mathrm{C}, 48 \mathrm{~h}$} & \multicolumn{2}{|c|}{ At $5^{\circ} \mathrm{C}, 10$ days } & & \\
\hline & Histamine & Tyramine & Histamine & Tyramine & Histamine & Tyramine \\
\hline Gram ne & & & & & & \\
\hline 31 & $8 / 31$ & $25 / 31^{\mathrm{a}}$ & $4 / 31$ & $19 / 31^{b}$ & nd & nd \\
\hline Gram po. & & & & & & \\
\hline LAB 17 & $0 / 17$ & $4 / 17$ & $0 / 17$ & $4 / 17$ & $0 / 5$ & $6 / 17$ \\
\hline Others 5 & $0 / 5$ & $1 / 5$ & $1 / 5$ & $1 / 5$ & $1 / 5$ & $2 / 5$ \\
\hline
\end{tabular}

nd: not determined.

${ }^{\text {a }}$ Positive reaction based on a visible clear halo around the colonies.

${ }^{\mathrm{b}}$ Weak positive reaction based on the appearance of purple colour around the colonies.

Table 2

Production of histamine and tyramine by selected bacterial strains isolated from Portuguese cold-smoked fish studied with HPLC method

\begin{tabular}{|c|c|c|c|c|c|}
\hline \multirow[t]{2}{*}{ Strain designation } & \multirow[t]{2}{*}{ Source } & \multirow[t]{2}{*}{ Storage week } & \multicolumn{2}{|c|}{ Supplemented in NB $\left(25\right.$ days at $\left.5{ }^{\circ} \mathrm{C}\right)$} & \multirow[t]{2}{*}{ Bacterial identification } \\
\hline & & & Histamine $(\mathrm{mg} / \mathrm{l})$ & Tyramine $(\mathrm{mg} / \mathrm{l})$ & \\
\hline & & & & & API $20 \mathrm{E}$ \\
\hline 4 & Plant C (salmon) & 1 & $0.00(\mathrm{n})$ & $1.30 \pm 0.04(w)$ & Aeromonas spp. \\
\hline 14 & Plant B (salmon) & 3 & $0.00(\mathrm{w})$ & $3.20 \pm 0.13(w)$ & S. liquefaciens/S. marcescens \\
\hline 63 & Plant C (salmon) & 2 & $73.7 \pm 0.85(\mathrm{n})$ & $11.71 \pm 0.40(\mathrm{w})$ & Pseudomonas spp. \\
\hline 70 & Plant C (salmon) & 3 & $0.00(\mathrm{n})$ & $7.27 \pm 0.20(\mathrm{w})$ & Pseudomonas spp. \\
\hline 72 & Plant B (salmon) & 3 & $0.00(\mathrm{n})$ & $8.06 \pm 0.08(\mathrm{n})^{\mathrm{a}}$ & P. fluorencens/putida \\
\hline 73 & Plant A (salmon) & 1 & $341.8 \pm 1.84(\mathrm{n})$ & $4.08 \pm 0.03(\mathrm{w})$ & Acinetobacter spp. \\
\hline 74 & Plant A (salmon) & 1 & $21.34 \pm 2.19(\mathrm{w})$ & $5.90 \pm 0.62(w)$ & Unknown \\
\hline \multirow[t]{2}{*}{ C. divergens } & Culture collection & & $0.00(\mathrm{n})$ & $8.25 \pm 0.10(\mathrm{p})$ & \\
\hline & & & \multicolumn{2}{|c|}{ Supplemented in NB (48 h at $\left.25^{\circ} \mathrm{C}\right)$} & \\
\hline LAB & & & & & API 50CHL \\
\hline 34 & $\begin{array}{l}\text { Plant C } \\
\text { (salmon-trout) }\end{array}$ & 1 & $0.00(\mathrm{n})$ & $453.6 \pm 0.92(p)^{b}$ & C. divergens \\
\hline 35 & $\begin{array}{l}\text { Plant C } \\
\text { (salmon-trout) }\end{array}$ & 1 & nd (n) & nd $(\mathrm{n})^{\mathrm{b}}$ & Lc. Lactis lactis 1 \\
\hline 37 & Plant B (salmon) & 3 & nd (n) & $\mathrm{nd}(\mathrm{n})^{\mathrm{b}}$ & Unknown \\
\hline 41 & Plant A (salmon) & 3 & $0.00(\mathrm{n})$ & $646.5 \pm 1.98(\mathrm{p})^{\mathrm{b}}$ & Lc. Lactis lactis 1 \\
\hline
\end{tabular}

nd: not determined; (p), (w) and (n): positive, weak positive and negative reaction, respectively, on decarboxylation agar (Niven et al., 1981).

${ }^{a}$ Development of weak yellow colour on Niven's agar.

${ }^{\mathrm{b}}$ Positive reaction on decarboxylation agar proposed by Maijala (1993).

When this method was used for screening of histamineproducing bacteria some histidine decarboxylase-producing bacteria may be excluded at the low $\mathrm{pH}$ of the medium (Chen et al., 1989).

A high detection rate using Niven's medium was observed especially when high levels of tyramine were produced at $25{ }^{\circ} \mathrm{C}$ (Table 1). The Gram-negative strains in general produced tyramine but low levels were found at $5{ }^{\circ} \mathrm{C}$ (Table 2). Confirmation by HPLC indicated one false negative bacterium identified as $P$. fluorescens/ putida, probably due to the excessive acid production that contributed to mask the purple colour on agar plates.

On the other hand, two strong tyramine-producing LAB strains that were identified as Lc. lactis lactis 1 and C. divergens were quantified (Table 2). The first bacterium used as a commercial starter culture has already been commented upon as a tyramine producer (Maijala,
1993). This author showed that the recognition was based on a HPLC method and not on using decarboxylation agar, even the modified decarboxylation agar for LAB strains. In our study, $35 \%$ of the LAB strains were detected as tyramine producers on the modified decarboxylation agar (Maijala, 1993) and of these only $24 \%$ of positive strains were detected by Niven's medium (Table 1). The basal composition of the modified decarboxylation agar was given by Niven et al. (1981), but to enhance the growth of LAB strains some metal sulphates and Tween 80 were added. $C$. divergens was identified as very common on cold-smoked fish and is part of the spoilage microflora. Jorgensen et al. (2000a) reported that when the end of shelf-life was based on the Multiple Compound Quality Index (MCQI) for coldsmoked salmon, the minimal spoilage levels of $C$. divergens would be $10^{9} \mathrm{cfu}^{-1}$. The same authors showed that $C$. divergens and Lactobacillus sakei subsp. carnosus 
enhanced the spoilage activity of $S$. liquefaciens or $H$. alvei but this was not shown in the case of $P$. phosphoreum. The inclusion of the term "metabiotic spoilage association" for situations where two or more species exchange metabolites, which results in spoilage, was introduced by Jorgensen et al. (2000b). In the current study, bacteria having amine-producing capacity were only studied individually and no studies using mixture cultures (cocktail) were made.

\section{Conclusions}

Tyrosine-agar was shown to be a good indicator medium for detection of bacteria that produce high levels of tyramine, since typical colonies surrounded by a translucent halo were easily distinguished. Also, a modified decarboxylation agar proposed by Maijala (1993) was shown to be more promissory for use on detection of tyramine LAB strains, probably due to the medium composition.

From the results obtained using Niven's medium, and especially for detection of histamine, considering that by-products such as ammonia can deliver false positive results, further research is needed to increase the selectivity of these differential media and identify the cause of the false negative results obtained with the genera Acinetobacter and Pseudomonas.

\section{References}

Actis, L. A., Smoot, J. C., Barancin, C. E., \& Findlay, R. H. (1999). Comparison of differential plating media and two chromatography techniques for the detection of histamine production in bacteria. Journal of Microbiological Methods, 39, 79-90.

Chen, C. M., Wei, C. I., Koburger, J. A., \& Marshall, M. R. (1989). Comparison of four agar media for detection of histamine- producing bacteria in Tuna. Journal of Food Protection, 52(11), $808-813$.

Davidson, C. M., \& Cronin, F. (1973). Medium for the selective enumeration of lactic acid bacteria from foods. Applied Microbiology, 26(3), 439-440.

Joosten, H. M. L. J., \& Northolt, M. D. (1989). Detection, growth, and amine-producing capacity of Lactobacilli in cheese. Applied and Environmental Microbiology, 55(9), 2356-2359.

Jorgensen, L. V., Dalgaard, P., \& Huss, H. H. (2000b). Multiple compound quality index for cold-smoked salmon (Salmo salar) developed by multivariate regression of biogenic amines and $\mathrm{pH}$. Journal of Agriculture and Food Chemistry, 48, 2448-2453.

Jorgensen, L. V., Huss, H. H., \& Dalgaard, P. (2000a). The effect of biogenic amine production by single bacterial cultures and metabiosis in cold-smoked salmon. Journal of Applied Microbiology, 89(6), 920-934.

Krause, I., Bockhardt, A., Neckermann, H., Henle, T., \& Klostermeyer, H. (1995). Simultaneous determination of amino acids and biogenic amines by reversed-phase high-performance liquid chromatography of the dabsyl derivates. Journal of Chromatography A, $715,67-79$

Leisner, J. J., Millan, J. C., Huss, H. H., \& Larsen, L. M. (1994). Production of histamine and tyramine by lactic acid bacteria isolated from vacuum-packed sugar-salted fish. Journal of Applied Bacteriology, 76, 417-423.

Maijala, R. L. (1993). Formation of histamine and tyramine by some lactic acid bacteria in MRS-broth and modified decarboxylation agar. Letters in Applied Microbiology, 17, 40-43.

Niven, C. F., Jeffrey, M. B., \& Corlett, D. A. (1981). Differential plating medium for quantitative detection of histamine-producing bacteria. Applied Environmental Microbiology, 41, 321-322.

ten Brink, B., Damink, C., Joosten, H. M. L. J., \& Huis in't Veld, J. H. J. (1990). Occurence and formation of biologically active amines in foods. International Journal of Food Microbiology, 11, 73-84.

Truelstrup Hansen, L., \& Huss, H. H. (1995). Comparison of the microflora isolated from spoiled cold-smoked salmon from three smokehouses. Food Research International, 31, 703-711.

Truelstrup Hansen, L., 1995. Quality of chilled, vacuum packed coldsmoked salmon. Ph.D. Thesis, Department of Seafood Research, Danish Institute of Fisheries Research, Lyngby, Denmarck.

Spreekens, K. J. A. (1974). The suitability of a modification of Long and Hammer's medium for the enumeration of more fastidious bacteria from fresh fisheries products. Archiv fuer Lebensmittlehygiene, 25, 213-219. 